\title{
Research on Traditional Aesthetic Philosophy in the Japanese Literature Lili Dong ${ }^{1, a}$ \\ ${ }^{1}$ College of Foreign Language, Jilin Agricultural University, Jilin, Changchun, China, 130118 \\ aemail,
}

\section{Keywords: Traditional Aesthetic Philosophy, Japanese Literature}

\begin{abstract}
The distinguishing characteristic of Japanese literature and literature of other nations is that forming a series of unique literary concepts and aesthetic categories. Appeared in many classic works of literature aesthetics, we can find from varying degrees to common characteristics, and throughout the history of Japanese National Literature Development. This paper describes the basic essence of aesthetic philosophy "Unseen" 'impermanence' "Mono no aware 'exhibited in Japanese literature.
\end{abstract}

\section{Introduction}

The cornerstone of Japan's traditional culture and aesthetic consciousness is --- true. The so-called true, that art is a true reflection of the human world around, will the emotions lyrical, emphasizing the author stands only "sincerity" and explore the natural beauty in real life, do not advocate floating Lai false style, is an art realism on. "Leaves Collection" is particularly prominent in the works reflect this. People "Leaves Collection" era of the pursuit of a simple natural beauty, this awareness is present in all things from the ancient "permanent change" the hearts of the people of the world, the so-called "secular certainly optimistic" view of the world. Therefore, literary works of that period mainly reflects is true.

After this, the Japanese aesthetic consciousness in the real foundation rise to - mono no aware, from simple exclamation of "mono no aware" to "was one heart" to "sad" to express the mono no aware and sympathy, seamless lovingly touched emotions inclined to sentimental. "Sad" Take the poor as the main object of love (emotional body), show people the truth, so "sad" subjective feelings will increase goes from emotional to sexual touching appeal. Therefore, only the "sad" can not fully express the Japanese literature that touched the feelings, fun and beauty concept, which in turn sublimation - was sad. It can be said that philosophy is the essence of Japanese culture and the essence of the entire Japanese literature, is also understood that the Japanese national character key. Mr. Ye Weiqu in his book "Japanese Trend History of Literature", the explanation was sad as "objects of the sense of the performance of a tenderness and compassion blended mood", the object may be a person or thing, but also to expand the social world around . In short, the sad thing is deep philosophy like one kind of feeling caused by the scenes. This concept established its leading position in the Japanese literature, an overview of most Japanese literature, all permeated with such a literary concept.

The novel fusion of landscape and human lyrical style, depicts the idea of literature --- was sad, this point of view, the traditional Japanese aesthetic characteristics can glimpse from the literature, and have been implanted ingrained the works. View the book, human and social profound insight and sharp criticism for numerous many dramatis personae given individualized characterizations of each characters unique, vivid, impressive. Through grand, elaborate ideas and nuanced psychological description, deeply dig out the inherent real people. To create the world would marvel macro magnum opus, in addition to her experience with the court life of the outside, more importantly, her profound literary accomplishment and Chinese literature, music, painting, and her deep knowledge of the delicate sensitive nature so inextricably linked. In addition, the need to mention is her poetry quite a learning and reference and get a lot of inspiration from the "Everlasting Regret", making the work of the Japanese aristocracy among men and women love and life of debauchery matter was comprehensive description profound. 


\section{Three Basic Aesthetic Concepts in Japanese Literature}

In the "MAK Culture" period of Japanese history, pseudonym so that people can fully use their own language freely express ideas and creation. At the same time, Japanese culture at an unprecedented rate to move forward, there has been a splendid sight, and made remarkable achievements in literature. Japanese literature has shown the unique aesthetic taste and nationality, are "MAK Culture" period begins to form. This paper describes three aspects of classical Japanese literature the most basic, the most typical representative of the aesthetic ideas.

The Beauty of "Impermanence". Japanese Buddhism absorption, transformation, integration is closely related to the social reality in Japan, where "impermanence" View is particularly prominent. Buddhism speaks of "impermanence", often it refers to the person's death, so the Buddhist concept of impermanence, in fact, on the "death" of views and ideas. The Japanese accepted "impermanence" is the "uncertain outlook" philosophical understanding of impermanence, all phenomena without me. Circulation sense of impermanence of all things to some extent, penetrate into the spiritual life of the Japanese people and Japanese literature and associated. As a chant, lyrical sense of mono no aware sparked sympathy. In view of this, "impermanence" and other Japanese aesthetic sense of mystery and the like, as it is just a feeling; a called "a sense of impermanence" is more appropriate emotional things. Japan and song, haiku and other literary works often use the word "impermanence."

Kobo Daishi in the creation of the song, describes the ancient Japanese understanding of impermanence. The song "impermanence" had a very strong religious thought. By familiar natural phenomena, sigh passage of time, things change, life is like a flowering, youth goes, time is getting chant Buddhist thought. Ping An initial special situation, because only the aristocracy can reading literacy, this period of "impermanence" is mainly reflected in the aristocratic literature. Creation aristocratic literature reached its highest level and is not a song but a Story. Story as a literary genre, the Japanese nation is a unique form of creation, can be regarded as fiction. Story peak known as the peace of hovering in the aristocratic upper class, exhibit "MAK culture" pointing to the same period of aesthetic taste, and its theme is the fate of impermanence.

To the safe end of Japan's "impermanence" beauty bursting out a more gorgeous brilliant literary flower. The pinnacle of Japanese Wars Story of "Heike Monogatari" about flat with Taira clan headed by the rise and fall of the story, which you can interpret the development path of the Buddhist concept of impermanence. They imitate the opening "Nirvana Sutra" protect the country in the next volume of the product in the sentence, "News of the Garden Abode chime, Sara various colors of trees, the winner of the ratio of bad rhyme line characterization of impermanence.". In "Pride comes before a fall, spring night like a dream. Strong final death, like dust in the wind," begins to become theme throughout the text. Nakamura said: "I feel impermanence and monks, appeared in Japan's end of the old ruling class decline, the new ruling class established feudal system conversion of the old ruling class in decline, prompting its former supporters off worldly desires, instead. yearned for religion. "in a dead, decline and other beauty disillusionment impermanence of life is the main theme of the story, as summarized Buddhist impermanence, karma and other ideas, it is the Buddhist concept of impermanence triggered" grief. "

Kamakura early duck in its collection of essays impermanence in Buddhist tone, lamenting the impermanence of the world, natural disasters, social unrest, acutely aware of the vagaries of life, and describes himself to eat and sleep , angrily escapist situation.

The Beauty of Mono No Aware. Japan has been in a "civilized surrounding" position, the countries affected by foreign cultural influence is very big. To the Heian period, formed its own unique spiritual and cultural, aesthetic sense of another dominant in this period $\mathrm{n}$ is "mono no aware '. "Mono no aware" is a traditional Japanese literature, poetics, aesthetics is an important concept. It can be said, do not understand "Mono no aware" can not grasp the essence of classical Japanese literature, it is difficult to correct in-depth understanding of the "Tale of Genji", and song, music, etc. can be represented by the traditional Japanese literature, it can not recognize ethnic characteristics of Japanese Literature .

"Mono no aware" first appeared in Literary Review "purple text essentials," "The Tale of Genji 
jade comb" and other writings. Motoori Norinaga that "each season landscape, is the perception was sad thing." In Motoori Norinaga opinion, "Mono no aware" is "to see and hear things in contact with heartfelt sigh." With a graceful, slender, quiet, sad colors concept similar to "sigh."

Deep mono no aware difficult hermit was also love. God on behalf of dynasties, ancient songs, singing sigh interest than those who carry it. Masterpiece songs are as much. Today almost to the common people's song, Love Story many, the natural tendency of really human also. straight, changing with the times, bitter, sadness, resentment coffee, anger onions, fun, joy, etc. everyone. life feeling many of situation, the best seen in love in this Story but G do things this world mono no aware and deep regret making the heart of the reader. If love, then a lot of deep fine at the human, is the essence of all of sadness was difficult. consequent to the special theme of love, the love of which is , thinking heart of love, all sorts of sadness situation like in the very fine pen and ink to write, describe mono no aware was leaving the show. "this argument is not only illustrates the" Tale of Genji "core content and mood, but also shows the" mourning was "beauty and mono no aware throughout the United States and Japanese literature closely linked. From "Kojiki songs" Sad Love Song Wan, the "Tale of Genji" attributed to disillusionment romance, <Ancient and Modern Song> Chang $<$ New Kokinwaksyuu $>$ "a lot of talk in the longing for the song until Kawabata, Yukio Mishima Cardiff pen futile love, embodies the people to see through things in the world of transience and sigh, "sad thing," the affectionate finish.

Needless to say, "Mono no aware" in "thing," and "Matter poems," "sad thing" in "thing" is the same word "material" is not a specific usage and flexible terms. Feelings become the main human object, all are "things'." Thing "can be both natural objects, can also be a human or a human creation. Gazing at the joys and mono no aware of the object generated in the process of joy, anger, are" material sad. "is not specific to the object being moved is inspired by a certain" mono no aware ", which gave birth to the understanding of Japanese literature psychological principles of Japanese literature thinking that as long as the heart has been able to move sprouted out Literary creation. Therefore, the Japanese believe that the starting point of literature is simple and slim thinking based on the origin. on the other hand, literature is no specific purpose. aimless and slender is the main characteristic of Japanese literature, showing that "mono no aware" is the subtleties of Japanese literature.

The Beauty of "Unseen". Aesthetic consciousness literature, art, literature and other areas of Japan in the world during the "Unseen." In Wakayama world, the establishment of "Unseen" aesthetic consciousness is Fujiwara-Jun, he is the author and song, only the pursuit and song the external form of beauty, but also the pursuit of "implication there is sound, lingering filled," the beauty of silence, the slender beauty. after the end of the Warring States period, regaining the aesthetic sense of stability and harmony of life in the world to pursue, still implies war period that life impermanence meant "Unseen." this aesthetic sense of a kind of deep potential of Buddhist thought. even on the song in the world for the first time on the aesthetic sense of the Japanese were positive discussion. even songs on the "fly leaves" and other words, by the Buddhism describes the nature of plant life short impermanence concept, formed a "Unseen" aesthetic meaning ridiculed "Unseen" aesthetic consciousness affects and songs to even the song's creation, and later penetrated into aesthetic consciousness Noh, tea in, and " silence "for the Edo irresolute harmonic inherited. the most emphasis on" Unseen "aesthetic sense is Zeami, Zeami enabled music performance having a fine character, and laid the foundation for Art. In Su Tzu parterre" to "flower" discusses the "Unseen" in America. can the music "flower" stressed the objective of the United States, he stressed the appeal, criticize explicit realistic, rough agitation under taste performances, advocates of natural harmony and quiet solitude on taste "Unseen" beauty show. "Unseen" beauty consciousness is in Momoyama era formed a unique world of tea ceremony "Tacitus"' silence "aesthetic ideas. Thousands led by Hugh Lee tea ceremony master who, from a wild flower and a common vessel to explore the United States "surprised" the spirit of the tea ceremony has become an important factor in the world to abandon the luxury, the pursuit of simplicity, how hidden in the heart of "surprised "show it is quiet (surprised) pursuit of the essence of tea. In a small simple space, within the specified time defined able to feel infinitely rich inner beauty, which embodies the spirit of a tea 
ceremony in a will.

"Unseen," the sense of beauty for future generations of haiku later works inherited. Matsuo Basho harmonic irresolute theory of "silence" attaches particular importance, showing a subtle, Qingyi, ethereal, unseen essence of poetry "surprised" and "silence" of lies spoken Zen enlightenment realm. Irresolute sentence as "surprised" and "silence" implies both the solitude of the affective component, outlook uncertain impact is obvious. Beauty of things will have a "short "' solitude "feeling, is not unique to the Japanese aesthetic sense of aesthetics in the West there is a similar expression. But in Japan, this expression has always run through people's aesthetic consciousness. Matsuo Basho except "Fuga "' Tacitus' "Death," but also a "food", "fine" and as understanding of beauty "food" refers to "wither' 'wither"' dying ", etc., and" fine "embodies a" delicate beauty ", both of which are inextricably linked and impermanence. in short, the Japanese aesthetic consciousness, there is a feeling originated in Buddhism, has been passed only understand the" Unseen "exists to Japanese literature and culture have a deeper understanding.

\section{Conclusion}

Since ancient times, we see the literati understanding experience of beauty and relentless pursuit, that was sad, is the unseen, is the realm of the millennium, the millennium of the United States. Although the history of Japanese literature is far from old China, thinking that no Western avant-garde, but both she Concurrently, unique, out of his own glory. Although the ideology and culture of Japan has a considerable degree of one-sided and limitations in the development, but the unique beauty still continue to attract many people to taste her, to explore her.

\section{References}

[1] Jia Xinzhang, Li Jingyuan. Literature, Vol. 6 (2014) No 53, p.25-26

[2] Wang Yunhui, Wang Qunyong. Fujian Normal College, Vol. 12 (2015) No 27, p.74-76

[3] Qian Xiyuan, Jing Jianfen. Literature Innovation, Vol. 30 (2014) No 19, p.144-145

[4] Wang Kuailiang. Japanese Culture, Vol. 29 (2008) No 27, p.21-23

[5] Zhang Gongxu, Sun Jing. World Culture, Vol. 8 (2013) No 27, p.57-60 